\title{
One year outcomes in patients with acute lung injury randomised to initial trophic or full enteral feeding: prospective follow-up of EDEN randomised trial
}

Dale M Needham associate professor ${ }^{123}$, Victor D Dinglas research program supervisor ${ }^{12}$, O Joseph Bienvenu associate professor ${ }^{145}$, Elizabeth Colantuoni assistant scientist ${ }^{16}$, Amy W Wozniak research associate ${ }^{16}$, Todd W Rice assistant professor ${ }^{7}$, Ramona O Hopkins professor ${ }^{89}$, for the NIH NHLBI ARDS Network

${ }^{1}$ Outcomes After Critical Illness and Surgery Group, Johns Hopkins University, Baltimore, MD 21205, USA; ${ }^{2}$ Division of Pulmonary and Critical Care Medicine, School of Medicine, Johns Hopkins University, Baltimore, MD 21205, USA; ${ }^{3}$ Department of Physical Medicine and Rehabilitation, School of Medicine, Johns Hopkins University, Baltimore, MD 21205, USA; ${ }^{4}$ Department of Psychiatry and Behavioral Sciences, School of Medicine, Johns Hopkins University, Baltimore, MD 21205, USA; ${ }^{5}$ Department of Mental Health, Bloomberg School of Public Health, Johns Hopkins University, Baltimore, MD 21205, USA; ${ }^{6}$ Department of Biostatistics, Bloomberg School of Public Health, Johns Hopkins University, Baltimore, MD 21205, USA; ${ }^{7}$ Division of Allergy, Pulmonary, and Critical Care Medicine, School of Medicine, Vanderbilt University, Nashville, TN 37232, USA; ${ }^{8}$ Department of Medicine, Pulmonary and Critical Care Division, Intermountain Medical Center, Murray, UT 84107, USA; ${ }^{9}$ Psychology Department and Neuroscience Center, Brigham Young University, Provo, UT 84602, USA

\begin{abstract}
Objective To evaluate the effect of initial low energy permissive underfeeding ("trophic feeding") versus full energy enteral feeding ("full feeding") on physical function and secondary outcomes in patients with acute lung injury.

Design Prospective longitudinal follow-up evaluation of the NHLBI ARDS Clinical Trials Network's EDEN trial

Setting 41 hospitals in the United States.

Participants 525 patients with acute lung injury.

Interventions Randomised assignment to trophic or full feeding for up to six days; thereafter, all patients still receiving mechanical ventilation received full feeding.

Measurements Blinded assessment of the age and sex adjusted physical function domain of the SF-36 instrument at 12 months after acute lung injury. Secondary outcome measures included survival; physical, psychological, and cognitive functioning; quality of life; and employment status at six and 12 months.

Results After acute lung injury, patients had substantial physical, psychological, and cognitive impairments, reduced quality of life, and impaired return to work. Initial trophic versus full feeding did not affect mean SF-36 physical function at 12 months (55 (SD 33) v 55 (31),
\end{abstract}

$\mathrm{P}=0.54)$, survival to 12 months $(65 \% v 63 \%, \mathrm{P}=0.63)$, or nearly all of the secondary outcomes.

Conclusion In survivors of acute lung injury, there was no difference in physical function, survival, or multiple secondary outcomes at 6 and 12 month follow-up after initial trophic or full enteral feeding.

Trial Registration NCT No 00719446

\section{Introduction}

Optimal nutritional strategies for mechanically ventilated patients in the intensive care unit are uncertain. There is some evidence and recommendations to support both initial full energy enteral feeding ("full feeding") and low energy permissive underfeeding ("trophic feeding") with different risks and benefits described ${ }^{1-7}$ The Acute Respiratory Distress Syndrome Clinical Trials Network of the National Heart, Lung and Blood Institute published a large, multicentre randomised open label trial of initial trophic compared with full enteral feeding for up to six days in patients with acute lung injury (the "EDEN trial"). ${ }^{8}$ This trial found no significant difference in short term outcomes, including mortality and days without ventilation. Because nutritional interventions have the potential for longer term effects, ${ }^{9}$ and because longer term outcomes of patients in 
intensive care units might differ from short term results, study outcomes also should be assessed over a longer time frame. ${ }^{10-15}$ Evaluation of longer term functional outcomes is especially important in patients with acute lung injury because trophic feeding can exacerbate protein limitations in the intensive care unit, ${ }^{16}$ and such malnutrition might underlie important muscle loss, ${ }^{17}$ persistent muscle weakness, and functional impairment in these patients. ${ }^{18-22}$ Moreover, post hoc data analyses from a previous phase II randomised trial in mechanically ventilated patients in intensive care showed that they were more likely to be discharged to a rehabilitation facility than home with trophic rather than full feeding. ${ }^{23}$

We undertook a prospective longitudinal evaluation of patient outcomes at six and 12 months after acute lung injury in participants from the EDEN study. We assessed patients' physical function, quality of life, functional activities, fatigue, psychological symptoms, cognition, and employment status at six and 12 months after acute lung injury and evaluated the effect of initial trophic compared with full enteral feeding on physical function and secondary outcome measures.

\section{Methods}

This study, the ARDS Network Long Term Outcomes Study (ALTOS), was designed to prospectively follow patients enrolled in several ARDS Network trials, including the EDEN trial. Three of the 44 hospitals included in the EDEN study did not participate in this follow-up study. Consenting patients from the 41 participating hospitals were eligible for enrolment into this prospective longitudinal study, with follow-up from April 2008 to April 2012.

\section{Patients}

Details of the EDEN eligibility criteria and study intervention have been reported previously (see appendix). ${ }^{8}$ Over the first six days of the EDEN trial, the trophic feeding group received, on average, $1672 \mathrm{~kJ} /$ day ( $25 \%$ of caloric goal), while the full feeding group received $5434 \mathrm{~kJ} /$ day ( $80 \%$ of caloric goal). ${ }^{8} \mathrm{We}$ excluded patients from the EDEN trial if they met any of the following criteria, based on their status before admission to hospital for acute lung injury: cognitive impairment (evaluated from the medical record and interview with the patient and/or proxy), non-English speaking, homelessness, or aged under 18. The first 272 of 1000 patients enrolled in EDEN were simultaneously randomised to a separate blinded trial (the OMEGA study) that examined a nutritional supplement containing omega 3 fatty acids and antioxidants compared with an isoenergetic isovolemic control in a $2 \times 2$ factorial design. ${ }^{24}$ All EDEN patients were managed with simplified versions of lung protective ventilation ${ }^{25}$ and fluid conservative haemodynamic management ${ }^{26}$ protocols, with blood glucose control accomplished with institution specific protocols for insulin targeting about $4-8 \mathrm{mmol} / \mathrm{L}$, with tighter control permitted. ${ }^{8}$

\section{Study procedures}

Trained research staff, blinded to treatment allocation, telephoned patients three months after the onset of acute lung injury to provide a reminder about the follow-up study and to obtain updated contact information for the patient and designated proxies. They completed the study assessments at six and 12 months. Published methods were used to minimise loss to follow-up. ${ }^{27-32}$ When patients could not complete the assessments by telephone, study assessments were completed by mail (5\% of all assessments) and/or by designated proxies (only for the functional performance inventory and the employment secondary outcome measures, representing $9 \%$ of these assessments).

\section{Primary and secondary outcomes}

The primary outcome was the physical function domain of SF-36 (version 2) instrument, ${ }^{33}$ adjusted for age and sex (range 0-100; higher score is better). Secondary outcomes included the age and sex adjusted SF-36 mental health domain (range 0-100; higher score is better) and the SF-36 physical and mental health summary quality of life norm based scores (range 0-100; higher score is better; mean 50 (SD 10)); the EQ-5D-3 $\mathrm{L}^{34}$ generic quality of life instrument with a utility score ${ }^{35}$ (range -0.11-1.0; higher score is better) and visual analogue scale score (range $0-100$; higher score is better); the functional performance inventory ${ }^{36}{ }^{37}$ overall functional activity score and subscale scores for physical exercise, maintaining household, and body care (for each, range 0-3; higher score is better); functional assessment of chronic illness therapy ${ }^{38}{ }^{39}$ fatigue interval scale score (range 0-100; higher score is better, with scores $\leq 68$ indicating fatigue); hospital anxiety and depression scale ${ }^{40}$ subscale scores for anxiety and depression symptoms (for each, range 0 - 21 ; lower score is better, with scores $\geq 8$ indicating substantial symptoms); impact of events scale-revised ${ }^{41}$ score for post-traumatic stress disorder symptoms (range 0-4; lower score is better, with scores $\geq 1.6$ indicating substantial symptoms ${ }^{42}$ ); the mini-mental state examination telephone version converted score ${ }^{43}$ for cognition (range 0-30; higher score is better, with scores $\leq 24$ indicating impairment); and employment status (full or part time work $v$ unemployed).

\section{Statistical analyses}

All analyses were by intention to treat and performed with SAS version 9.2 (SAS Institute, Cary, NC). A two sided $\mathrm{P}<0.05$ was considered significant. Statistical analyses were conducted according to an a priori written statistical analysis plan. A Kaplan-Meier curve was used to display survival during the follow-up period, with a comparison of trophic versus full feeding groups with the log rank test. To evaluate change over time (12v six months) for the entire study population, we compared continuous and binary outcome measures, ignoring treatment assignment, using linear and binomial (identity link) regression models, respectively, with generalised estimating equations ${ }^{44}$ and an exchangeable correlation model. To quantify the treatment effect for the continuous and binary outcome measures assessed at six and 12 months, we created linear and logistic regression models, using generalised estimating equations with an exchangeable correlation model and an indicator for treatment group (trophic $v$ full feeding), follow-up time (12v six months), and the interaction of treatment group and time. In a secondary analysis for the primary outcome variable we extended the above model to test for a statistical interaction between OMEGA randomised assignment and EDEN treatment group (trophic $v$ full feeding). We performed additional secondary analyses for the primary outcome variable for a priori patient subgroups at baseline (body mass index (BMI) $<25,25$ to $<30, \geq 30$ ), acute lung injury subgroup $\left(\mathrm{PaO}_{2} / \mathrm{FiO}_{2} \leq 200 v \mathrm{PaO}_{2} / \mathrm{FiO}_{2}>200\right)$, shock (present $v$ absent), and a priori statistical interactions (age and APACHE III score as continuous variables). Missing data were excluded from statistical analyses as only 1-6\% of each outcome instrument evaluated had any missing data. 


\section{Results}

There were 951 patients enrolled at the EDEN hospitals participating in this study. Baseline patient characteristics were comparable between the trophic and full feeding groups, with a mean age of 52, $49 \%$ women, $79 \%$ white, and $82 \%$ living independently (table $1 \Downarrow$ ). Of these 951 patients, $155(16 \%)$ who survived until hospital discharge did not meet eligibility criteria for this follow-up study, leaving 796 patients of whom 508 (64\%) survived until 12 months after randomisation (fig $1 \Downarrow$ ), with no difference between groups (trophic $v$ full feeding estimated 12 month survival $65 \% v 63 \%$; $\log \operatorname{rank} \mathrm{P}=0.63$ ).

\section{Patient outcomes at six and $\mathbf{1 2}$ months}

At six and 12 months, there were 525 and 510 consenting survivors eligible for follow-up, with only $11(2 \%)$ and $23(<5 \%)$ missed at the respective follow-up times (fig $2 \Downarrow$ ). Mean (SD) lengths of stay in the intensive care unit and in hospital for the 525 consenting patients surviving until six month follow-up were 14 (12) and 22 (16) days, respectively. Survivors had substantially lower physical and mental quality of life scores compared with age and sex matched population norms (table $2 \Downarrow$ ), with a 12 month mean score on the physical function domain of 55 (SD 32) compared with the population norm of 82 (SD 9) $(\mathrm{P}<0.001)$. Functional activity level, as measured by the overall mean score on the functional performance inventory, at 12 months was 2.0 (SD 0.7), indicating "some" difficulty. These physical outcomes at 12 months were significantly improved from the six month assessment (table 2). During the 12 month follow-up, 87 (18\%) and 57 (12\%) patients were admitted to rehabilitation and skilled nursing facilities, respectively, with 267 (56\%) requiring either these types of inpatient rehabilitation and nursing care or outpatient physiotherapy. Substantial symptoms of anxiety, depression, and post-traumatic stress disorder were common at 12 months, affecting $42 \%, 37 \%$, and $23 \%$ of survivors, respectively, without significant improvement from the six month assessment (table 2). Cognitive impairment was present in $21 \%$ of survivors at 12 months, reduced from $25 \%$ at six months $(\mathrm{P}=0.06)$. Among survivors at 12 month follow-up, 223 (47\%) of the 474 who reported on their employment status before admission to hospital were employed; of these previously employed survivors, 107 (48\%) were not working at 12 month follow-up, with 82 (77\%) of them attributing their unemployment to health related reasons.

\section{Comparison of trophic $v$ full feeding}

There was no significant difference in the mean age and sex adjusted SF-36 physical function domain score (55 (SD 33) $v$ 55 (SD 31) between the initial trophic and full feeding groups; mean difference adjusted for age and sex 2 (95\% confidence interval -4 to $7, \mathrm{P}=0.54)$. There was no interaction between OMEGA randomised assignment and trophic versus full feeding group on the physical function domain score. With the exception of the SF-36 mental health measures that favoured trophic feeding, there were no significant differences between trophic and full feeding groups for all other secondary outcome measures, including functional activities, fatigue, psychological symptoms, cognition, and employment status (table $3 \Downarrow$, fig $3 \Downarrow$ ). Across the primary outcome and almost all secondary outcomes, the treatment effects at the six and 12 month assessment did not significantly differ. In addition, there were no differences in secondary analyses of the a priori subgroups and statistical interactions.

The 12 month cumulative incidence of admission to a physical rehabilitation facility was greater in the trophic group (57 (23\%) $v 30$ (14\%), $\mathrm{P}=0.01)$. There were no significant differences between the trophic and full feeding groups in new residence in a healthcare facility at 90 days $(19(7 \%) v 11(4 \%), \mathrm{P}=0.21)$ or in the 12 month cumulative incidence of admission to skilled nursing facilities $(29(12 \%) v 28(13 \%), \mathrm{P}=0.70)$ or receipt of outpatient physiotherapy (121 (49\%) v99 (46\%), $\mathrm{P}=0.50)$.

\section{Discussion}

Over 12 months of follow-up of patients with acute lung injury from 41 hospitals participating in the EDEN trial, there was no difference in physical function (primary outcome), 12 month survival, or physical, psychological and cognitive function, or employment status at six and 12 months between those randomised to initial trophic versus full enteral feeding. The cumulative mortality was $36 \%$, with survivors showing substantial physical, psychological and cognitive impairments, with reduced quality of life, substantial need for institutionalisation and physical rehabilitation, and impaired return to work.

\section{Comparison with other studies}

Consistent with the findings of mainly previous single centre studies of people with acute lung injury, ${ }^{182}$ 45-49 this multicentre study showed impairments across multiple physical, psychological, and cognitive domains, collectively referred to as "post-intensive care syndrome." ${ }^{50}$ Unlike physical outcomes, mean scores for psychological and cognitive outcomes did not significantly improve between six and 12 months. It is notable that patients' baseline status for many of these outcomes cannot be measured before onset of acute lung injury, raising the possibility that these were pre-existing impairments; however, the patients evaluated were relatively young, lived independently without assistance at baseline, and were free from cognitive impairments before the illness. Moreover, the observed impairments in quality of life scores at six and 12 months were substantially greater than estimated quality of life scores before intensive care reported in other groups of acute lung injury survivors. ${ }^{51}{ }^{52}$ In addition, other large cohort studies, with prospective measurement of status before intensive care, have shown important new subsequent impairments in physical, psychological, and cognitive outcomes ${ }^{53-57}$ Finally, the magnitude and incidence of these impairments is supported by the high rate of use of rehabilitation, new institutionalisation, and inability to return to work after acute lung injury.

Nutritional strategies in intensive care units, as evaluated in this randomised trial of initial trophic versus full enteral feeding, had no effect on a wide spectrum of outcome measures reported by patients, with no differences between groups for the physical function primary outcome or for nearly all secondary physical, psychological, cognitive and employment outcomes. There is little clinical research investigating the long term outcomes of nutritional strategies in the intensive care unit; hence, limiting specific insights into the potential reasons for these findings and emphasising the importance of further research on this issue. Of note, about half of patients in the trophic feeding group eventually received full feeding after the initial six day period, as per the EDEN protocol. Hence, perhaps the overall duration of differences in feeding strategies in the EDEN patients was not long enough to contribute to differences in outcomes. Alternatively, perhaps within one nutritional strategy, potential benefits were counter balanced by harms, with each mediated by different mechanisms associated with the strategy.

Mean differences in SF-36 mental health scores were significant between the feeding groups, but relatively small in magnitude ${ }^{58}$ 
and not supported by significant differences in any of the specific psychological outcome measures (such as symptoms of anxiety, depression, and post-traumatic stress disorder); such differences should therefore be cautiously interpreted. Moreover, as previously observed in a post hoc analysis from a similar phase II randomised trial of nutrition in intensive care, ${ }^{23}$ patients in the trophic feeding group were significantly more likely than patients in the full feeding group to be admitted to a rehabilitation facility over 12 month follow-up. Despite this finding, there were no significant differences in other physical, psychological, and cognitive outcomes between groups at six and 12 months, and there were no differences in new residence in a healthcare facility at 90 days or in the 12 month cumulative incidence of admission to a skilled nursing facility or receipt of outpatient physiotherapy. Further exploration of shorter term outcomes and of muscle strength and performance based physical function measures (such as the six minute walk test) could help inform this finding as trophic feeding might have short term effects or physiological effects not evaluated in this study.

\section{Limitations}

The study has several strengths, including detailed prospective longitudinal assessment of about 500 patients recruited from 41 hospitals. In addition, at six and 12 month follow-up, only $2 \%$ and $<5 \%$ of consenting patients missed their visits. This study also has potential limitations. Firstly, the EDEN trial primarily evaluated relatively young, well nourished, overweight patients with acute lung injury with pneumonia or non-pulmonary sepsis. The study's findings might not therefore be generalisable to critically ill patients who are older, malnourished, and without infection. Secondly, the study evaluated only patient/proxy reported outcomes obtained by phone or mail, without any performance based assessments (such as the six minute walk test) from direct evaluation. Thirdly, the open label design of the EDEN trial has the potential to introduce bias. In our study, however, the patient outcomes assessors and investigators were blinded to randomised group assignment, and the written statistical analysis plan and study data were finalised before unblinding the treatment allocation. Finally, as functional outcome measures can be assessed only in survivors, mortality after randomisation could introduce bias in understanding the effect of a randomised treatment on functional outcomes. ${ }^{59}$ This issue is of less importance in this study, however, because the randomised treatment allocation did not differentially affect mortality.

\section{Conclusion}

This multicentre longitudinal study of outcomes at six and 12 months after acute lung injury showed substantial physical, cognitive, and psychological impairments, with reduced quality of life, substantial need for institutionalisation and physical rehabilitation, and impaired return to work. An initial strategy of trophic or full calorie enteral feeding did not affect patients' physical function or multiple secondary outcome measures at six and 12 month follow-up after acute lung injury.

We thank all patients and their proxies who participated in the study. We thank Melissa McCullough, Mardee Merrill, Elizabeth Vayda,

Jonathan Gellar, Laura Methvin, Gita Byraiah, Shirani Rajan, Elizabeth Fuller, and Cassie Wicken who assisted with data collection; and William Flickinger, and Christopher Mayhew who assisted with data management.

The National Heart, Lung, and Blood Institute Acute Respiratory Distress Syndrome (ARDS) Clinical Trials Network: University of Washington,
Harborview (*L Hudson, S Gundel, C Hough, M Neff, K Sims, A Ungar, T Watkins); Baystate Medical Center ( ${ }^{\star} \mathrm{J}$ Steingrub, M Tidswell, E Braden, L DeSouza, J Germain, C Kardos, D Kelley, L Kozikowski, S Ouellette); Baylor College of Medicine (K Guntupalli, V Bandi, C Pope, C Ross); Johns Hopkins University ( ${ }^{*}$ R Brower, H Fessler, D Hager, P Mendez-Tellez, D Needham, K Oakjones); Johns Hopkins Bayview Medical Center (J Sevransky, A Workneh); University of Maryland (C Shanholtz, D Herr, H Howes, G Netzer, P Rock, A Sampaio, J Titus); Union Memorial Hospital (P Sloane, T Beck, D Highfield, S King); Washington Hospital Center (B Lee, N Bolouri); Cleveland Clinic Foundation ( ${ }^{*} \mathrm{H}$ P Wiedemann, R W Ashton, D A Culver, T Frederick, J A Guzman, J J Komara Jr, A J Reddy); University Hospitals of Cleveland (R Hejal, M Andrews, D Haney); MetroHealth Medical Center (A F Connors, S Lasalvia, J D Thornton, E L Warren); University of Colorado Hospital, Aurora ( ${ }^{*}$ M Moss, E L Burnham, L Gray, J Maloney, M Mealer); Denver Health Medical Center (I Douglas, K Overdier, K Thompson, R Wolken); Rose Medical Center (S Frankel, J McKeehan); Swedish Medical Center (M L Warner); Saint Anthony's Hospital (T Bost, C Higgins, K Hodgin); Duke University (*N Maclntyre, L Brown, C Cox, M Gentile, J Govert, N Knudsen); University of North Carolina (S Carson, L Chang, S Choudhury, W Hall, J Lanier); Vanderbilt University ( ${ }^{*}$ A P Wheeler, G R Bernard, M Hays, S Mogan, T W Rice); Wake Forest University ('R D Hite, K Bender, A Harvey, P E Morris, Mary Ragusky); Moses Cone Memorial Hospital (P Wright, S Groce, J McLean, A Overton); University of Virginia (J Truwit, K Enfield, M Marshall); LDS Hospital and Intermountain Medical Center (*A Morris, A Austin, S Barney, S Brown, J Fergeson, H Gallo, T Graydon, C Grissom, E Hirshberg, A Jephson, N Kumar, R Miller, D Murphy, J Orme, A Stow, L Struck, F Thomas, D Ward, L Weaver); LDS Hospital (P Bailey, W Beninati, L Bezdijan, T Clemmer, S Rimkus, R Tanaka); McKay Dee Hospital (C Lawton, D Hanselman); Utah Valley Regional Medical Center (K Sundar, W Alward, C Bishop, D Eckley, T Hill, B Jensen, K Ludwig, D Nielsen, M Pearce); University of California, San Francisco ( ${ }^{*}$ M A Matthay, C Calfee, B Daniel, M Eisner, O Garcia, K Kordesch, K Liu, N Shum, H Zhou); University of California, San Francisco, Fresno (M W Peterson, J Blaauw, K Van Gundy); University of California, Davis (T Albertson, B Morrissey, E Vlastelin); Louisiana State University Health Sciences Center-New Orleans (*B deBoisblanc, A Antoine, D Charbonnet, J Hunt, P Lauto, A Marr, G Meyaski, C Romaine, R Tejedor); Earl K Long Medical Center, Baton Rouge General Medical Center Mid-City and Baton Rouge General Medical Center Bluebonnet (S Brierre, J Byrne, T Jagneaux, C LeBlanc, K Moreau, C Thomas); Ochsner Clinic Foundation (S Jain, D Taylor, L Seoane); Our Lady of the Lake Medical Center (C Hebert, J Thompson); Tulane Medical Center (F Simeone, J Fearon) Clinical Coordinating Center: Massachusetts General Hospital and Harvard Medical School ( ${ }^{*} \mathrm{D}$ Schoenfeld, M Guha, E Hammond, N Lavery, P Lazar, R Morse, C Oldmixon, N Ringwood, E Smoot, B T Thompson, R Wilson) National Heart, Lung and Blood Institute: A Harabin, S Bredow, M Waclawiw, G Weinmann Data and Safety Monitoring Board: R G Spragg (chair), A Slutsky, M Levy, B Markovitz, E Petkova, C Weijer Protocol Review Committee: J Sznajder (chair), M Begg, E Israel, J Lewis, S McClave, $P$ Parsons. *Principal investigator.

Contributors: DMN and $\mathrm{ROH}$ contributed to conception and design of the manuscript. DMN, VDD, OJB, EC, AWW, TWR, and ROH contributed to analysis and interpretation of data. DMN drafted the article and all other authors critically revised it for important intellectual content. All authors gave final approval of the manuscript version to be published. DMN and EC are guarantors.

Funding: National Heart, Lung and Blood Institute funded this follow-up study (N01HR56170, R01HL091760 and 3R01HL091760-02S1) and the EDEN trial (contracts HHSN268200536165C to HHSN268200536176C and HHSN268200536179C). All researchers are independent of the funding bodies. The funding bodies had no role in the study design; in the collection, analysis and interpretation of data; 


\section{What is already known on this topic}

A large multisite randomised trial showed no difference in short term mortality and days without ventilation in patients with acute lung injury randomised to initial trophic or full enteral feeding in intensive care

Given differences in protein and total caloric intake between these two feeding strategies, evaluation of the effect on patients' longer term functional outcomes is important

\section{What this study adds}

In 525 patients with acute lung injury recruited from 41 US hospitals, substantial physical, psychological, and cognitive impairments were common at six and 12 month follow-up

Randomisation to initial trophic or full enteral feeding did not affect physical function (primary outcome), survival, or psychological and cognitive outcomes at six and 12 month follow-up

in the writing of the report; and in the decision to submit the manuscript for publication.

Competing interests: All authors have completed the ICMJE uniform disclosure form at www.icmje.org/coi_disclosure.pdf (available on request from the corresponding author) and declare: no support from any organisation for the submitted work; no financial relationships with any organisations that might have an interest in the submitted work in the previous three years; no other relationships or activities that could appear to have influenced the submitted work.

Ethical approval: The study was approved by the institutional review boards at each participating hospital, the two centres performing outcome assessments, and the EDEN data and safety monitoring board; and informed consent was given by all patients or their proxy.

Data sharing: No additional data available

1 Barr J, Hecht M, Flavin KE, Khorana A, Gould MK. Outcomes in critically ill patients before and after the implementation of an evidence-based nutritional management protocol. Chest 2004:125:1446-57.

2 Rubinson L, Diette GB, Song X, Brower RG, Krishnan JA. Low caloric intake is associated with nosocomial bloodstream infections in patients in the medical intensive care unit. Crit Care Med 2004;32:350-7.

3 Ibrahim EH, Mehringer L, Prentice D, Sherman G, Schaiff R, Fraser V, et al. Early versus late enteral feeding of mechanically ventilated patients: results of a clinical trial. JPEN J Parenter Enteral Nutr 2002;26:174-81.

4 Krishnan JA, Parce PB, Martinez A, Diette GB, Brower RG. Caloric intake in medical ICU patients: consistency of care with guidelines and relationship to clinical outcomes. Chest 2003;124:297-305.

5 Dickerson RN, Boschert KJ, Kudsk KA, Brown RO. Hypocaloric enteral tube feeding in critically ill obese patients. Nutrition 2002:18:241-6.

6 Arabi YM, Haddad SH, Tamim HM, Rishu AH, Sakkijha MH, Kahoul SH, et al. Near-target caloric intake in critically ill medical-surgical patients is associated with adverse outcomes. JPEN J Parenter Enteral Nutr 2010;34:280-8.

7 Martin CM, Doig GS, Heyland DK, Morrison T, Sibbald WJ. Multicentre, cluster-randomized clinical trial of algorithms for critical-care enteral and parenteral therapy (ACCEPT). CMAJ 2004;170:197-204.

8 Rice TW, Wheeler AP, Thompson BT, Steingrub J, Hite RD, Moss M, et al. Initial trophic vs full enteral feeding in patients with acute lung injury: the EDEN randomized trial. JAMA 2012;307:795-803.

9 Griffiths RD. Nutrition and survival in intensive care. Med Klin Intensivemed Notfmed 1998;35:3-9.

10 Woon FL, Dunn CB, Hopkins RO. Predicting cognitive sequelae in survivors of critical illness with cognitive screening tests. Am J Respir Crit Care Med 2012;186:333-40.

11 Iwashyna TJ. Trajectories of recovery and dysfunction after acute illness, with implications for clinical trial design. Am J Respir Crit Care Med 2012;186:302-4.

12 Zeiher BG, Artigas A, Vincent JL, Dmitrienko A, Jackson K, Thompson BT, et al. Neutrophil elastase inhibition in acute lung injury: results of the STRIVE study. Crit Care Med 2004;32:1695-702.

13 Cooper DJ, Rosenfeld JV, Murray L, Arabi YM, Davies AR, D'Urso P, et al. Decompressive craniectomy in diffuse traumatic brain injury. N Engl J Med 2011;364:1493-502.

14 Spragg RG, Bernard GR, Checkley W, Curtis JR, Gajic O, Guyatt G, et al. Beyond mortality: future clinical research in acute lung injury. Am J Respir Crit Care Med 2010;181:1121-7.

15 Angus DC, Laterre PF, Helterbrand J, Ely EW, Ball DE, Garg R, et al. The effect of drotrecogin alfa (activated) on long-term survival after severe sepsis. Crit Care Med 2004;32:2199-206.

16 Griffiths RD. Nutrition for critically ill patients: how much is enough? JAMA 2012;307:845-6.

17 Puthucheary Z, Rawal J, Ratnayake G, Harridge S, Montgomery H, Hart N. Neuromuscular blockade and skeletal muscle weakness in critically ill patients: time to rethink the evidence? Am J Respir Crit Care Med 2012;185:911-7.

18 Herridge MS, Cheung AM, Tansey CM, Matte-Martyn A, Diaz-Granados N, Al Saidi F, et al. One-year outcomes in survivors of the acute respiratory distress syndrome. $N$ Engl $J$ Med 2003;348:683-93.

19 Herridge MS, Tansey CM, Matte A, Tomlinson G, Diaz-Granados N, Cooper A, et al. Functional disability 5 years after acute respiratory distress syndrome. N Engl J Med 2011;364:1293-304

20 Stevens RD, Dowdy DW, Michaels RK, Mendez-Tellez PA, Pronovost PJ, Needham DM. Neuromuscular dysfunction acquired in critical illness: a systematic review. Intensive Care Med 2007;33:1876-91.
21 De Jonghe B, Sharshar T, Lefaucheur JP, Authier FJ, Durand-Zaleski I, Boussarsar M et al. Paresis acquired in the intensive care unit: a prospective multicenter study. JAMA 2002;288:2859-67.

22 Bienvenu OJ, Colantuoni E, Mendez-Tellez PA, Dinglas VD, Shanholtz C, Husain N, et al. Depressive symptoms and impaired physical function after acute lung injury: a 2-year longitudinal study. Am J Respir Crit Care Med 2012;185:517-24

23 Rice TW, Mogan S, Hays MA, Bernard GR, Jensen GL, Wheeler AP. Randomized trial of initial trophic versus full-energy enteral nutrition in mechanically ventilated patients with acute respiratory failure. Crit Care Med 2011;39:967-74.

24 Rice TW, Wheeler AP, Thompson BT, deBoisblanc BP, Steingrub J, Rock P. Enteral omega-3 fatty acid, gamma-linolenic acid, and antioxidant supplementation in acute lung injury. JAMA 2011;306:1574-81.

25 Brower RG, Matthay MA, Morris A, Schoenfeld D, Thompson BT, Wheeler A. Ventilation with lower tidal volumes as compared with traditional tidal volumes for acute lung injury and the acute respiratory distress syndrome. The Acute Respiratory Distress Syndrome Network. N Engl J Med 2000;342:1301-8.

26 Wiedemann HP, Wheeler AP, Bernard GR, Thompson BT, Hayden D, deBoisblanc B, et al. Comparison of two fluid-management strategies in acute lung injury. $N$ Engl $\mathrm{J}$ Med 2006;354:2564-75.

27 Robinson KA, Dennison CR, Wayman DM, Pronovost PJ, Needham DM. Systematic review identifies number of strategies important for retaining study participants. J Clin Epidemiol 2007:60:757-65.

28 Tansey CM, Matte AL, Needham D, Herridge MS. Review of retention strategies in longitudinal studies and application to follow-up of ICU survivors. Intensive Care Med 2007;33:2051-7.

29 Hall EA, Zuniga R, Cartier J, Anglin MD, Danila B, Ryan T, et al. Staying in touch: a fieldwork manual of tracking procedures for locating substance abusers in follow-up studies. 2nd ed. UCLA Integrated Substance Abuse Programs, 2003.

30 Roary MC, Hill MN, Bone LR, Levine DM. Innovative strategies that dispel the myths about urban young black men with high blood pressure. Cardiovasc Rev Rep 2000;21:129-37.

31 Coday M, Boutin-Foster C, Goldman ST, Tennant J, Greaney ML, Saunders SD et al. Strategies for retaining study participants in behavioral intervention trials: retention experiences of the NIH Behavior Change Consortium. Ann Behav Med 2005:29(suppl):55-65.

32 Hunt JR, White E. Retaining and tracking cohort study members. Epidemiol Rev 1998;20:57-70.

33 Ware JE Jr, Kosinski M, Dewey JE. How to score version 2 of the SF-36 Health Survey QualityMetric Incorporated, 2000.

34 EuroQol Group. EuroQol-a new facility for the measurement of health-related quality of life. Health Policy 1990;16:199-208.

35 Shaw JW, Johnson JA, Coons SJ. US valuation of the EQ-5D health states: development and testing of the D1 valuation model. Med Care 2005;43:203-20.

36 Leidy NK. Psychometric properties of the functional performance inventory in patients with chronic obstructive pulmonary disease. Nurs Res 1999;48:20-8.

37 Leidy NK, Knebel A. Clinical validation of the Functional Performance Inventory in patients with chronic obstructive pulmonary disease. Respiratory Care 1999;44:932-9.

38 Cella D, Lai JS, Chang CH, Peterman A, Slavin M. Fatigue in cancer patients compared with fatigue in the general United States population. Cancer 2002;94:528-38.

39 Cella D, Nowinski CJ. Measuring quality of life in chronic illness: the functional assessment of chronic illness therapy measurement system. Arch Phys Med Rehabil 2002;83(12 supp 2):S10-7.

40 Zigmond AS, Snaith RP. The hospital anxiety and depression scale. Acta Psychiatr Scand 1983:67:361-70

41 Weiss DS. The impact of event scale-revised. In: Wilson JP, Keane TM, eds. Assessing psychological trauma and PTSD: a practitioner's handbook. 2nd ed. Guilford Press, 2004:168-89.

42 Bienvenu JB, Williams JB, Yang A, Hopkins RO, Needham DM. Posttraumatic stress disorder in acute lung injury survivors: evaluating the impact of event scale-revised. Chest 2013 (in press).

43 Newkirk LA, Kim JM, Thompson JM, Tinklenberg JR, Yesavage JA, Taylor JL. Validation of a 26-point telephone version of the mini-mental state examination. J Geriatr Psychiatry Neurol 2004;17:81-7.

44 Diggle PJ, Liang K-Y, Zeger SL. Analysis of longitudinal data. Oxford University Press, 1994.

45 Hopkins RO, Weaver LK, Pope D, Orme JF, Bigler ED, Larson-LOHR V. Neuropsychological sequelae and impaired health status in survivors of severe acute respiratory distress syndrome. Am J Respir Crit Care Med 1999;160:50-6.

46 Dowdy DW, Eid MP, Dennison CR, Mendez-Tellez PA, Herridge MS, Guallar E, et al. Quality of life after acute respiratory distress syndrome: a meta-analysis. Intensive Care Med 2006;32:1115-24

47 Davydow DS, Desai SV, Needham DM, Bienvenu OJ. Psychiatric morbidity in survivors of the acute respiratory distress syndrome: a systematic review. Psychosom Med 2008;70:512-9.

48 Hopkins RO, Weaver LK, Collingridge D, Parkinson RB, Chan KJ, Orme JF Jr. Two-year cognitive, emotional, and quality-of-life outcomes in acute respiratory distress syndrome. Am J Respir Crit Care Med 2005;171:340-7. 
49 Mikkelsen ME, Christie JD, Lanken PN, Biester RC, Thompson BT, Bellamy SL, et al. The adult respiratory distress syndrome cognitive outcomes study: long-term neuropsychological function in survivors of acute lung injury. Am J Respir Crit Care Med 2012;185:1307-15

50 Needham DM, Davidson J, Cohen H, Hopkins RO, Weinert C, Wunsch H, et al. Improving long-term outcomes after discharge from intensive care unit: report from a stakeholders conference. Crit Care Med 2012;40:502-9.

51 Gifford JM, Husain N, Dinglas VD, Colantuoni E, Needham DM. Baseline quality of life before intensive care: a comparison of patient versus proxy responses. Crit Care Med 2010;38:855-60.

52 Scales DC, Tansey CM, Matte A, Herridge MS. Difference in reported pre-morbid health-related quality of life between ARDS survivors and their substitute decision makers. Intensive Care Med 2006;32:1826-31.

53 Iwashyna TJ, Ely EW, Smith DM, Langa KM. Long-term cognitive impairment and functional disability among survivors of severe sepsis. JAMA 2010;304:1787-94.

54 Ehlenbach WJ, Hough CL, Crane PK, Haneuse SJ, Carson SS, Curtis JR, et al. Association between acute care and critical illness hospitalization and cognitive function in older adults. JAMA 2010;303:763-70.

55 Barnato AE, Albert SM, Angus DC, Lave JR, Degenholtz HB. Disability among elderly survivors of mechanical ventilation. Am J Respir Crit Care Med 2011;183:1037-42.

56 Iwashyna TJ, Netzer G, Langa KM, Cigolle C. Spurious inferences about long-term outcomes: the case of severe sepsis and geriatric conditions. Am J Respir Crit Care Med 2012;185:835-41.
57 Davydow DS, Hough CL, Russo JE, Von KM, Ludman E, Lin EH, et al. The association between intensive care unit admission and subsequent depression in patients with diabetes. Int J Geriatr Psychiatry 2012;27:22-30.

58 Wyrwich KW, Tierney WM, Babu AN, Kroenke K, Wolinsky FD. A comparison of clinically important differences in health-related quality of life for patients with chronic lung disease, asthma, or heart disease. Health Serv Res 2005;40:577-91.

59 Varadhan R, Weiss CO, Segal JB, Wu AW, Scharfstein D, Boyd C. Evaluating health outcomes in the presence of competing risks: a review of statistical methods and clinical applications. Med Care 2010;48(6 suppl):S96-105.

60 Steiger JH, Fouladi RT. Noncentrality interval estimation and the evaluation of statistical models. In: Harlow LL, Mulaik SA, Steiger JH, eds. What if there were no significance tests? Erlbaum, 1997:221-58

61 Hedges LV, Olkin I. Statistical methods for meta-analysis. Academic Press, 1985.

\section{Accepted: 19 February 2013}

\section{Cite this as: BMJ 2013;346:f1532}

This is an open-access article distributed under the terms of the Creative Commons Attribution Non-commercial License, which permits use, distribution, and reproduction in any medium, provided the original work is properly cited, the use is non commercial and is otherwise in compliance with the license. See: http://creativecommons.org/licenses/by$\mathrm{nc} / 2.0 /$ and http://creativecommons.org/licenses/by-nc/2.0/legalcode. 


\section{Tables}

Table 1/ Characteristics of patients with acute lung injury according to randomisation to initial trophic or full enteral feeding. Figures are means (SD) unless stated otherwise ${ }^{*}$

\begin{tabular}{|c|c|c|c|}
\hline Characteristic & All patients $(n=951)$ & Trophic feeding $(n=481)$ & Full feeding $(n=470)$ \\
\hline \multicolumn{4}{|l|}{ Baseline patient data } \\
\hline Age (years) & $52(16)$ & $52(16)$ & $52(15)$ \\
\hline No (\%) women & $468(49)$ & $227(47)$ & $241(51)$ \\
\hline No (\%) white & $717(79)$ & $362(79)$ & $355(79)$ \\
\hline \multicolumn{4}{|l|}{ No (\%) by previous residence: } \\
\hline Home independently & $780(82)$ & $396(82)$ & $384(82)$ \\
\hline Home with help or professional help & $108(11)$ & $53(11)$ & $55(12)$ \\
\hline Nursing, intermediate care, or rehabilitation facility & $42(4)$ & $19(4)$ & $23(5)$ \\
\hline Other & $21(2)$ & $13(3)$ & $8(2)$ \\
\hline BMI & $30(8)$ & $30(8)$ & $30(8)$ \\
\hline No (\%) with diabetes & $263(28)$ & $130(27)$ & $133(28)$ \\
\hline No (\%) with previous stroke with sequelae & $36(4)$ & $11(2)$ & $25(5)$ \\
\hline No (\%) receiving chronic haemodialysis & $30(3)$ & $12(2)$ & $18(4)$ \\
\hline \multicolumn{4}{|l|}{ Baseline intensive care data } \\
\hline No (\%) admitted to medical intensive care unit & $576(61)$ & $287(60)$ & $289(62)$ \\
\hline APACHE III score & $91(27)$ & $92(28)$ & $90(27)$ \\
\hline $\mathrm{PaO}_{2} / \mathrm{FiO}_{2}$ ratio & $165(81)$ & $167(80)$ & $163(82)$ \\
\hline No (\%) with $\mathrm{PaO}_{2} / \mathrm{FiO}_{2}$ ratio $\leq 200$ & $673(72)$ & $338(73)$ & $335(72)$ \\
\hline Albumin (g/L) & $23(7)$ & $23(7)$ & $23(7)$ \\
\hline \multicolumn{4}{|l|}{ No (\%) by primary lung injury risk factor: } \\
\hline Pneumonia & $617(65)$ & $321(67)$ & $296(63)$ \\
\hline Sepsis & $139(15)$ & $78(16)$ & $61(13)$ \\
\hline Aspiration & $91(10)$ & $40(8)$ & $51(11)$ \\
\hline Trauma & $36(4)$ & $17(4)$ & $19(4)$ \\
\hline Transfusions & $16(2)$ & $4(1)$ & $12(3)$ \\
\hline Other & $52(5)$ & $21(4)$ & $31(7)$ \\
\hline \multicolumn{4}{|l|}{ Daily intensive care data† } \\
\hline Morning glucose $(\mathrm{mmol} / \mathrm{L})$ & $7.38(1.83)$ & $7.10(1.38)$ & $7.66(1.38)$ \\
\hline Minimum glucose (mmol/L) & $6.33(1.5)$ & $6.16(1.39)$ & $6.49(1.55)$ \\
\hline Cumulative net fluid balance until day 7 (L) & $1.3(8.3)$ & $0.5(8.4)$ & $2.0(8.2)$ \\
\hline No (\%) with any dialysis during admission & $178(19)$ & $84(18)$ & $94(20)$ \\
\hline No (\%) with any vasopressor use & $450(48)$ & $231(48)$ & $219(47)$ \\
\hline Proportion of days per patient & $22(31)$ & $22(30)$ & $23(32)$ \\
\hline No (\%) with any corticosteroids & $327(36)$ & $178(38)$ & $149(33)$ \\
\hline Proportion of days per patient & $23(36)$ & $25(37)$ & $21(35)$ \\
\hline No (\%) with any narcotics & $895(94)$ & $451(94)$ & $444(95)$ \\
\hline Proportion of days per patient & $75(30)$ & $74(31)$ & $77(30)$ \\
\hline No (\%) with any neuromuscular blocker & $186(20)$ & $84(18)$ & $102(22)$ \\
\hline Proportion of days per patient & $7(20)$ & $7(19)$ & $8(20)$ \\
\hline \multicolumn{4}{|l|}{ Days without organ failure to day $28:$} \\
\hline Cardiovascular & $19(10)$ & $19(10)$ & $19(10)$ \\
\hline Renal & $20(11)$ & $20(11)$ & $19(11)$ \\
\hline Hepatic & $22(10)$ & $22(10)$ & $23(10)$ \\
\hline Coagulation & $23(9)$ & $22(10)$ & $23(9)$ \\
\hline
\end{tabular}




\section{Table 1 (continued)}

\section{Characteristic}

APACHE III=acute physiology and chronic health evaluation III; $\mathrm{PaO}_{2}=$ partial pressure of oxygen in arterial blood; FiO ${ }_{2}=$ fraction of inspired oxygen, $\mathrm{BMI}=$ body mass index.

*Proportions might not add to $100 \%$ because of rounding. Unknown or missing data: race $=43, \mathrm{BMI}=3, \mathrm{APACHE}_{\mathrm{III}} \mathrm{score}=24, \mathrm{PaO} / \mathrm{FiO}=18$, albumin $=35$, morning glucose $=4$, minimum glucose $=4$, dialysis $=1$, daily fluid balance=301, vasopressor use $=4$, corticosteroids $=41$, narcotics $=2$, neuromuscular blocker $=2$. †Data presented as overall average for each patient's mean value of available daily data. Medication data available until earlier of 48 hours after cessation of mechanical ventilation or day 10 for corticosteroids and vasopressors, and day 12 for narcotics and neuromuscular blockers. Proportions calculated among days in intensive care unit in which medication data were available. Glucose data available until earlier of 48 hours after cessation of mechanical ventilation or day 12 . Days without organ failure until day 28 calculated as previously published. ${ }^{8}$ 


\begin{tabular}{|c|c|c|c|c|}
\hline & 6 Months $(n=514)$ & 12 Months $(n=487)$ & Difference† $(95 \% \mathrm{Cl})$ & P Value \\
\hline \multicolumn{5}{|l|}{ Quality of life-SF-36 (population norm): } \\
\hline Physical function (82, SD 9) & $51(32)$ & $55(32)$ & $4(2$ to 5$)$ & $<0.001$ \\
\hline Physical health summary ( 50, SD 10$)$ & $38(12)$ & $39(13)$ & $2(1$ to 2$)$ & $<0.001$ \\
\hline Mental health $(76, \mathrm{SD} 3)$ & $64(26)$ & $65(25)$ & $1(-1$ to 3$)$ & 0.28 \\
\hline Mental health summary (50, SD 10) & $45(15)$ & $45(15)$ & $0(-1$ to 1$)$ & 0.94 \\
\hline \multicolumn{5}{|l|}{ Quality of life-EQ-5D: } \\
\hline Utility score & $0.68(0.25)$ & $0.71(0.24)$ & $0.02(0.00$ to 0.04$)$ & 0.02 \\
\hline Visual analogue scale & $68(22)$ & $69(22)$ & $2(0$ to 4$)$ & 0.08 \\
\hline \multicolumn{5}{|c|}{ Functional activities-functional performance inventory: } \\
\hline Overall score & $1.9(0.7)$ & $2.0(0.7)$ & $0.1(0.1$ to 0.1$)$ & $<0.001$ \\
\hline Physical exercise subscale & $1.6(0.9)$ & $1.6(0.9)$ & $0.1(0.0$ to 0.1$)$ & 0.03 \\
\hline Maintaining house subscale & $1.8(0.9)$ & $1.9(0.9)$ & $0.1(0.1$ to 0.2$)$ & $<0.001$ \\
\hline Body care subscale & $2.5(0.7)$ & $2.5(0.7)$ & $0.0(0.0$ to 0.1$)$ & 0.03 \\
\hline \multicolumn{5}{|l|}{ Fatigue-FACIT: } \\
\hline Interval score & $60(17)$ & $62(18)$ & $2(1$ to 3$)$ & 0.001 \\
\hline No (\%) with score $\leq 68$ & $342(71)$ & $304(67)$ & $-4(-8$ to -1$)$ & 0.02 \\
\hline \multicolumn{5}{|l|}{ Psychological symptomsł: } \\
\hline Anxiety score & $7(5)$ & $7(5)$ & $0(-10)$ & 0.21 \\
\hline No (\%) with score $\geq 8$ & $218(45)$ & $195(42)$ & $-3(-7$ to 2$)$ & 0.21 \\
\hline Depression score & $6(5)$ & $6(5)$ & $0(0$ to 0$)$ & 0.83 \\
\hline No (\%) with score $\geq 8$ & $179(37)$ & $170(37)$ & 0 ( -4 to 4$)$ & 0.88 \\
\hline Post-traumatic stress disorder score & $1.1(0.9)$ & $1.0(1.0)$ & $-0.1(-0.1$ to 0.0$)$ & 0.05 \\
\hline No (\%) with score $\geq 1.6$ & $122(26)$ & $107(23)$ & $-2(-6$ to 1$)$ & 0.23 \\
\hline \multicolumn{5}{|l|}{ Cognition—mini-mental state exam: } \\
\hline Score & $25(2)$ & $25(2)$ & $0(0$ to 0$)$ & 0.15 \\
\hline No (\%) with score $\leq 24$ & $120(25)$ & $96(21)$ & $-4(-8$ to 0$)$ & 0.06 \\
\hline No (\%) employed§ & $132(26)$ & $137(29)$ & $2(-1$ to 6$)$ & 0.13 \\
\hline
\end{tabular}

FACIT=functional assessment of chronic illness therapy; FPI=functional performance inventory

*Unknown or missing data: SF-36 physical function=29 (six months), 31 (12 months); SF-36 physical health summary=30, 33; SF-36 mental health=30, 32 ; SF-36 mental health summary=30, 33; EQ-5D utility score=28, 29; EQ-5D visual analogue scale=28, 30; FPI overall score $=16,15$; FPI physical exercise subscale=14, 15; FPI maintaining house subscale=13, 14; FPI body care subscale=13, 14; FACIT score=34, 32; anxiety score=31, 28; depression score=31, 29; post-traumatic stress disorder score $=37,31$; mini-mental state exam score $=31,37$; employment status $=9,7$.

†Calculations from linear or binomial (identity link) regression models based on generalising estimating equations with exchangeable correlation structure ${ }^{44}$ and indicator for time (12 $v 6$ month follow-up). "Difference" represents difference between 12 and 6 months in mean score for continuous measures or in proportion for binary measures.

$\ddagger$ Depression and anxiety symptoms measured with hospital anxiety and depression scale; symptoms of post-traumatic stress disorder measured with impact of events scale-revised.

§Employment at 6 and 12 months calculated for all patients regardless of reported baseline employment status. 
Table 3 | Outcomes ${ }^{*}$ at 12 months in patients with acute lung injury according to randomisation to initial trophic or full enteral feeding * Figures are means (SD) unless stated otherwise

Trophic feeding $(n=259)$

Full feeding $(n=228)$

Treatment effect $(95 \% \mathrm{Cl}) \dagger$

P value†

Quality of life-SF-36 (population norm)

\begin{tabular}{|c|c|c|c|c|}
\hline Physical function (82, SD 9) $\ddagger$ & $55(33)$ & $55(31)$ & $2(-4$ to 7$)$ & 0.54 \\
\hline $\begin{array}{l}\text { Physical health summary (50, SD } \\
\text { 10) }\end{array}$ & $39(14)$ & $40(13)$ & $0(-2$ to 3$)$ & 0.76 \\
\hline Mental health $(76$, SD 3$) \ddagger$ & $67(25)$ & $63(26)$ & $6(1$ to 10$)$ & 0.02 \\
\hline Mental health summary $(50$, SD 10$)$ & $46(15)$ & $43(15)$ & $4(1$ to 6$)$ & 0.01 \\
\hline \multicolumn{5}{|l|}{ Quality of life-EQ-5D } \\
\hline Utility score & $0.70(0.25)$ & $0.71(0.23)$ & $0.00(-0.04$ to 0.05$)$ & 0.75 \\
\hline Visual analogue scale & $71(22)$ & $68(23)$ & $3(-1$ to 7$)$ & 0.14 \\
\hline \multicolumn{5}{|c|}{ Functional activities-functional performance inventory: } \\
\hline Overall score & $2.0(0.7)$ & $2.1(0.7)$ & $-0.1(-0.2$ to 0.1$)$ & 0.28 \\
\hline Physical exercise subscale & $1.6(0.9)$ & $1.7(0.9)$ & $-0.1(-0.2$ to 0.1$)$ & 0.48 \\
\hline Maintaining house subscale & $1.9(0.9)$ & $2.0(0.9)$ & $0.0(-0.2$ to 0.1$)$ & 0.54 \\
\hline Body care subscale & $2.5(0.7)$ & $2.6(0.6)$ & $-0.1(-0.2$ to 0.0$)$ & 0.12 \\
\hline \multicolumn{5}{|l|}{ Fatigue-FACIT: } \\
\hline Interval score & $63(19)$ & $61(17)$ & $2(-1$ to 6$)$ & 0.16 \\
\hline No (\%) with score $\leq 68$ & $154(66)$ & $150(68)$ & $0.85(0.58$ to 1.24$)$ & 0.39 \\
\hline \multicolumn{5}{|l|}{ Psychological symptoms§: } \\
\hline Anxiety score & $7(5)$ & $7(5)$ & $0(-1$ to 0$)$ & 0.31 \\
\hline No (\%) score $\geq 8$ & $93(39)$ & $102(46)$ & 0.71 (0.49 to 1.02$)$ & 0.07 \\
\hline Depression score & $6(5)$ & $6(5)$ & $0(-1$ to 0$)$ & 0.28 \\
\hline No (\%) with score $\geq 8$ & $85(36)$ & $85(39)$ & $0.86(0.59$ to 1.25$)$ & 0.44 \\
\hline Post-traumatic stress disorder score & $0.9(0.9)$ & $1.1(1.0)$ & $-0.1(-0.3$ to 0.1$)$ & 0.20 \\
\hline No (\%) with score $\geq 1.6$ & $53(22)$ & $54(25)$ & 0.86 (0.57 to 1.32$)$ & 0.50 \\
\hline \multicolumn{5}{|l|}{ Cognition-mini-mental state exam: } \\
\hline Score & $25(2)$ & $26(2)$ & $0(0$ to 0$)$ & 0.45 \\
\hline No (\%) with score $\leq 24$ & $52(22)$ & $44(21)$ & 1.08 (0.69 to 1.69$)$ & 0.75 \\
\hline No (\%) employed & $69(27)$ & $68(30)$ & 0.86 (0.58 to 1.28$)$ & 0.46 \\
\hline
\end{tabular}

$\mathrm{FACIT}=$ functional assessment of chronic illness therapy; $\mathrm{FPI}=$ functional performance inventory.

*Unknown or missing data: SF-36=physical function 11 (full), 20 (trophic); SF-36=physical health summary=12, 21; SF-36 mental health=11, 21 ; SF-36 mental health summary=12, 21; EQ-5D utility score=8, 21; EQ-5D visual analogue scale=9, 21; FPI overall score=3, 12; FPI physical exercise subscale=3, 12; FPI maintaining house subscale=3, 11; FPI body care subscale=3, 11; FACIT score=8, 24; anxiety score=8, 20; depression score=8, 21; post-traumatic stress disorder score=9, 22; mini-mental state exam score=17, 20; employment status=2, 5 .

†Calculated from linear or logistic regression models based on generalising estimating equations with exchangeable correlation structure ${ }^{44}$ and indicator for treatment (trophic $v$ full feeding group), time (12 v6 month follow-up), and interaction of treatment group and time. Treatment effect represents mean difference in score for continuous measures and odds ratio for binary measures.

$\ddagger$ Adjusted for age and sex within linear regression model described above.

§Depression and anxiety symptoms measured with hospital anxiety and depression Scale and symptoms of post-traumatic stress disorder measured with impact of events scale-revised. 


\section{Figures}

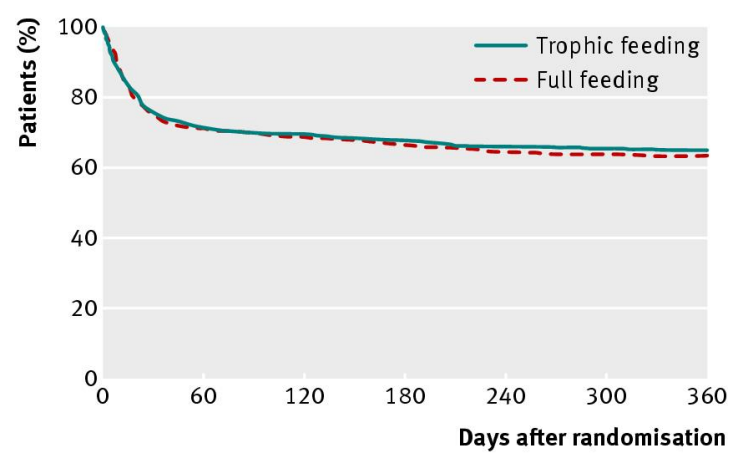

Fig 1 Survival until 12 months after randomisation. Curves at any time point represent proportion of patients surviving in study at that time. Two consenting patients were censored at date of six month assessment because of loss to follow-up thereafter. Patients known to be alive but who missed their 12 month follow-up were administratively censored at expected date of their 12 month assessment

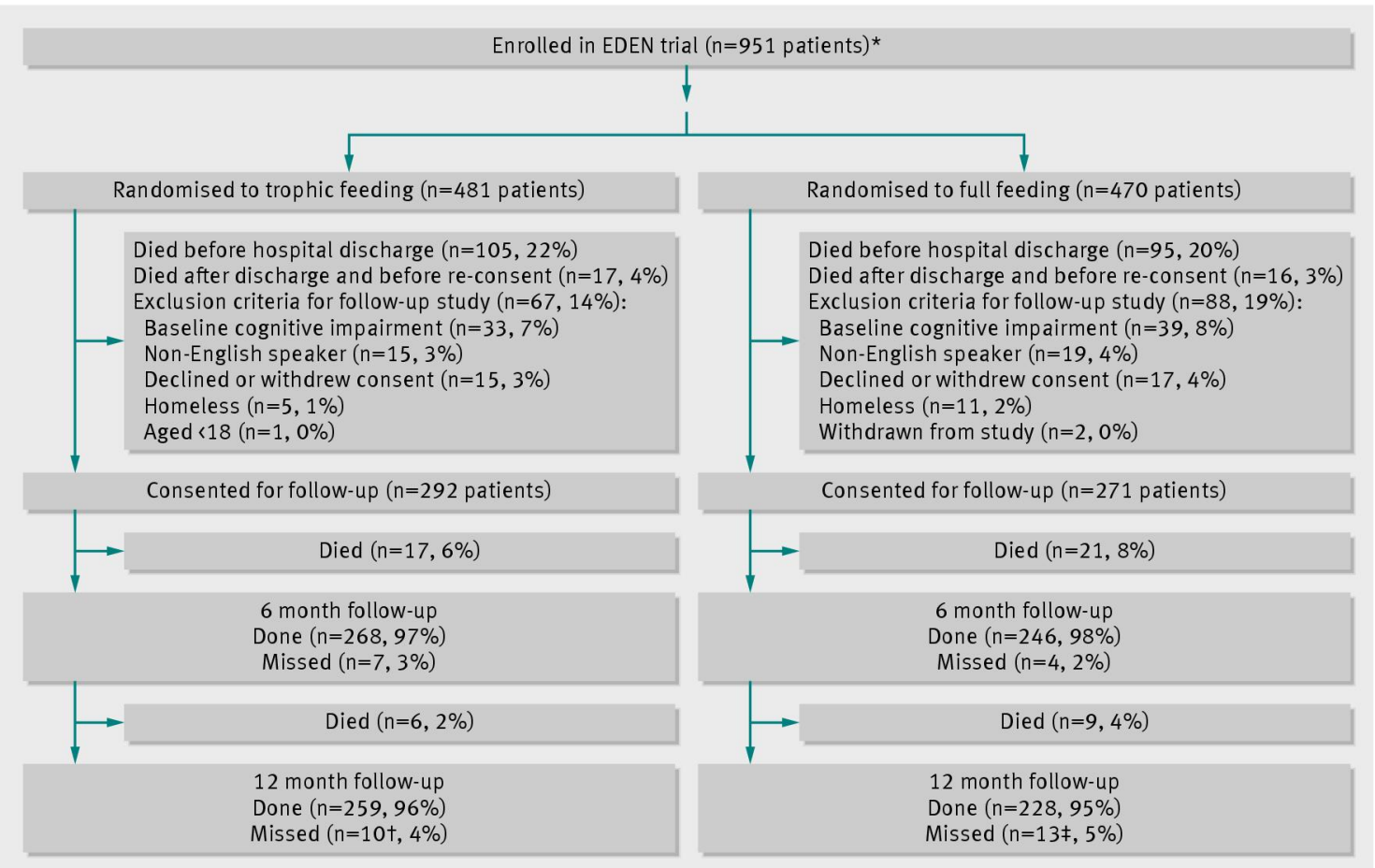

Fig 2 Enrolment and follow-up of patients with acute lung injury according to initial feeding regimen. *Three of 44 hospitals in EDEN trial did not participate in follow-up study, reducing original sample size from 1000 to 951; †eight known to be alive at 12 months, two others were censored for survival analysis; łknown to be alive at 12 months 
SF-36 physical function domain SF-36 physical health summary EQ-5D utility score

EQ-5D visual analogue scale Functional performance inventory Overall score

Physical exercise subscale Maintaining house subscale Body care subscale

SF-36 mental health domain SF-36 mental health summary FACIT fatigue score

FACIT fatigue score $\leq 68$

Hospital anxiety and depression scale Anxiety

Anxiety score $\geq 8$

Depression score

Depression score $\geq 8$

IES-R post-traumatic stress score

IES-R score $\geq 1.6$

Mini-mental state exam score

Mini-mental state exam score $\leq 24$ Employed

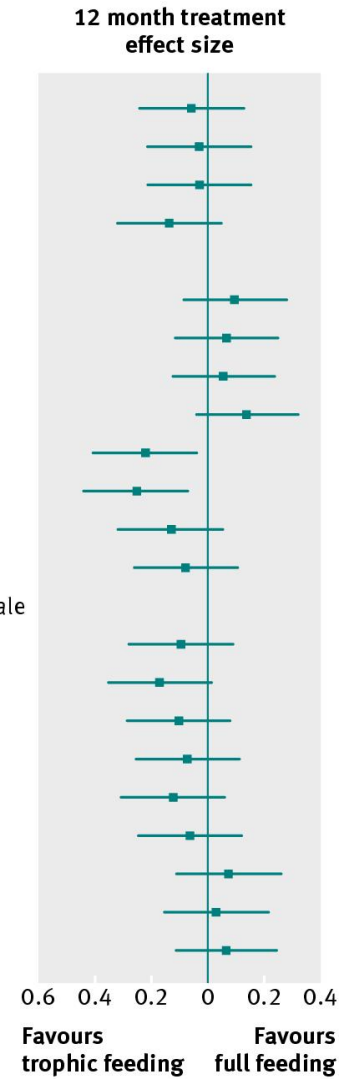

Fig 3 Effect size (treatment effect) of treatment intervention on primary outcome (SF-36 physical function domain adjusted for age and sex) and all secondary outcomes at 12 months. Effect size calculated as treatment effect (difference in means or proportions, see table 3) divided by pooled SD from trophic and full feeding groups. ${ }^{6061} \mathrm{FACIT}=$ functional assessment of chronic illness therapy, IES-R=impact of events scale-revised 